Vantage: Journal of Thematic Analysis

ISSN: 2582-7391

A Multidisciplinary Publication of Centre for Research, Maitreyi College, University of Delhi

October 2021, Volume 2, Issue 2

Original Research Article

\title{
Manipulating Mate-choice for a Quantitative Augmentation of a Biological Control Agent, Coccinella transversalis Fabricius
}

\author{
Mumtaj Jahan ${ }^{1}$ and Ahmad Pervez ${ }^{2 *}$ \\ ${ }^{1}$ Biocontrol Laboratory, Department of Zoology, Radhey Hari Govt. P.G. College, \\ Kashipur, Udham Singh Nagar - 244713, Uttarakhand, India \\ ${ }^{2}$ Department of Zoology, Sri Dev Suman Uttarakhand University, Rishikesh Campus, \\ Dehradun, Uttarakhand, India \\ *Correspondence: ahmadpervez@yahoo.com
}

\begin{abstract}
For food security and sustainable crop protection, it is a necessity to optimize the massrearing and augmentation of biocontrol agents of numerous aphid pests. Coccinellids, commonly known as ladybird beetles, are potential predators on several sucking pests and promising biocontrol agents. In the present investigation, laboratory experiments were performed to find out whether manipulation of mate choice in aphidophagous ladybird Coccinella transversalis Fabricius (Coleoptera: Coccinellidae) under varying mating status could influence reproductive output in terms of high fecundity. It was found that the mating status under the mate choice highly affects mating duration and fecundity. The mating commenced earlier under the presence of different males than the females in an arena. The mating lasted for a longer duration between virgin females and multi-mated males than vice-versa. The bouts in copula increased with an increase in the mating status in both sexes. Females of multi-mated status were more fecund than the unmated females. Thus, the present study will be useful for the manipulation of quantitative mass-rearing of $C$. transversalis for the biocontrol of aphids and thereby enhancing crop productivity and sustainable crop protection.
\end{abstract}

Keywords: Mating, mate-choice, fecundity, ladybirds, aphids, reproduction, augmentation 


\section{INTRODUCTION}

Agriculture provides a means of survival for people across the world, including India. According to the report of the Indian Brand Equity Foundation (IBEF), in September 2021 about 58\% of the Indian population depends upon agriculture for its survival, thereby it is a crucial factor for the Indian economy (Cagliarini \& Rush, 2011). India is the largest fruit and vegetable producer and the second-largest producer of rice and wheat (Dhawan, 2017). However agricultural production across the world requires a massive amount of fertilizer for increasing crop yield and pesticide incorporation to prevent yield loss caused by the pest population (Nayak et. al., 2020), their exposure to the population leads to health issues and their non-degradable nature contaminates water resources (Jain \& Ghosh, 2013; Koli \& Bharadwaj, 2018) and somehow make the crop pest to develop resistance.

Among crop pests, aphids (Homoptera: Aphididae) are the notorious ones, which comprise more than 5,000 species worldwide due to their higher diversification rate (Rebijith et. al., 2017; Loxdale et. al., 2017). They reduce the crop yield by feeding upon plant sap and make the plant susceptible to disease by transmitting phytopathogenic viruses (Guerrieria \& Digilio, 2008). Biological control is a practice under integrated pest management (IPM) program to manage and suppress the pest population by manipulating their natural enemies (Gray et. al., 2009; Neil \& Obrycki, 2009). Since the 19-century, ladybird beetles under biocontrol extensively reduce herbivorous pest population (Rondoni et al., 2020) and are known as the flagship of biocontrol by having predaceous habits (Roy \& Wanberg, 2007), under augmentative biocontrol as natural enemies, their periodic release achieves the rapid pest control (Lenteren, 2012).

The ladybird beetles (Coleoptera: Coccinellidae) are largely promiscuous and mate with single or many partners during their lifespan. However, the mating process asserts energy consumption can restrict the mating numbers in an organism by imposing the associated costs (Thornhill \& Alcock, 1983). The previous studies on the costs and benefits associated with multiple mating suggest that multiple mating benefits males in terms of enhanced paternity and fatherhood (Dubey et al., 2018). However, this imposes a costly trade-off to the males by gradually diminishing their sperm transferability and 
negatively affecting their longevity (Michaud et al., 2013; Perry \& Tse, 2013). On the other hand, multiple mating enhances egg-production in females coupled with eggviability by altering the rate of ovariole development (Pervez \& Maurice, 2011; Omkar \& Sahu, 2012; Mirhosseini et al., 2014; Shahid et al., 2016). However, it could be disadvantageous for females as it may reduce the longevity by physical injury and infection (Hust et al., 1995; Omkar \& Mishra, 2005).

The rate of mating success highly depends upon the informative cues to access the mating status of partners under the mate choice trials (Smith \& Harper, 2003). In other insect systems, like damselflies, male damselflies can detect the mating status of females, using chemical sensilla in their genitalia (Uhia \& Rivera, 2005), in seed beetles females detect male mating status by the production of ejaculate size (Fox et al., 1995). Whereas the production of sex pheromone occurs in females for increasing their chances of future mating (Verheggen et al., 2020), males access these olfactory stimuli to discriminate female mating status to attain fitness by choosing whether to mate or not (Thomas, 2011; Singh et al, 2020). Cuticular hydrocarbons are also involved in mate recognition and become more effective with time (Brown et al., 2006; Johansson \& Jones, 2007; Legrand et al., 2019).

The present study was conducted on an aphidophagous ladybird beetle, Coccinella transversalis Fabricius, which is found abundantly in the agricultural fields of the Oriental region (Pervez \& Omkar, 2005). It is a polyphagous biocontrol agent (Pervez et al., 2020), which feeds on a wide range of aphids and can also survive on non-aphid diets (Maurice et al., 2011; Shukla \& Jadhav, 2014). Coccinella transversalis adults attain sexual maturity soon after their emergence and early sexual activities increase their numbers in the fields (Pervez et al., 2021). However, complex mating behavior and response of $C$. transversalis need to be studied in the light of mate-choice and multiple mating to manipulate the optimization in their mass-production and augmentation in the laboratory. Thus, the laboratory experiment was designed to evaluate the pattern of mate choice in presence of con-specific mates for both males and females, how the copula and post-copulation parameters vary with the mate choice, and their effects on the reproductive output. 


\section{MATERIAL AND METHODS}

\subsection{Stock maintenance}

The adults of $C$. transversalis were first collected from the agricultural field near the college campus, Kashipur, Uttarakhand (India) (29²104`N, 789619`E) and brought to the laboratory. The beetles were paired in separate Petri dishes $(2.0 \mathrm{~cm} \mathrm{x} 9.0 \mathrm{~cm})$ and fed on ad libitum aphids. Aphis craccivora (Koch) infested on the twigs of host plant, Lablab purpureus (L.) Sweet. These Petri-dishes were kept in Environmental Test Chamber (Remi, Remi Instruments) maintained at $25 \pm 1^{\circ} \mathrm{C}$; $65 \pm 5 \%$ R.H.; 12L: 12D photoperiods. Adults mated and the females laid eggs, which were carefully transferred in different Petri dishes (size and food, as above) and reared from egg-hatch till the adult emergence. After emergence, the F1 adult beetles were sexed (by carefully examining their genitalia under a stereoscopic trinocular (Lyzer) connected to a PC (DELL) with camera attachment) and isolated in separate Petri dishes (size and food, as above) to be used for the experimentation. The experiment was conducted in the ladybird beetle active hours from 10:00 to 18:00 hours.

\subsection{Experimental Design}

To evaluate the mate-choice pattern in presence of conspecific mates, the experiment was designed in the two mate-choice combinations:

\section{(i) The combination I-mate choice in unmated males}

A 3-day-old unmated adult male, that was previously identified after examining the genitalia and reared in separate Petri-dish immediately after emergence, was used as an experimental model. This male was then kept together with adult females of four different mating statuses, viz. (i) unmated (Green), (ii) single mated (Blue), (iii) twice mated (Yellow), and (iv) multi-mated females (White) in a Petri dish (size as above). The mating status of these experimental females was discriminated by making colored spots (green, blue, yellow, and white) on anterior their elytra. This mating combination was repeated ten times $(\mathrm{n}=10)$.

\section{(ii) The combination II-mate choice in unmated females}

A 3-day-old virgin adult female that was previously identified after examining the genitalia and reared in a separate Petri dish immediately after emergence was used as an 
experimental model. This female was then kept in a Petri-dish with four males of different mating status, viz. (i) unmated (Green), (ii) single mated (Blue), (iii) twice mated (Yellow), and (iv) multi-mated males (White). The mating status of these experimental males was discriminated by making colored spots (green, blue, yellow, and white) on anterior their elytra. We replicated this mating combination ten times $(n=10)$.

For both mating combinations ( $\mathrm{i}$ and ii), as the mating commenced the unpreferred other mates were removed from the Petri dish so that the established mating is not interrupted or disturbed by others. During mating, the data on mating duration, time of mating commencement, latent period (time between genital contact to first body shaking), bouts (abdominal shaking) were recorded. As soon as the mating terminated, the adult male and female were isolated in separate Petri dishes (size and food, as above), and females were kept under observation for seven days to record fecundity and percent egg-viability. The data on mating duration, time of mating commencement, latent periods, bouts in copula, fecundity, and percent egg-viability were first subjected to the Kolmogorov-Smirnoff normality test for of distributions and Bartlett's test to ascertain homogeneity of variances using the statistical software, SAS (2002). Thereafter, the above data were subjected to one-way ANOVA using mating status as an independent variable (four levels) and mating duration, time of mating commencement, latent periods, bouts in copula, fecundity, and percent egg-viability as dependent variables using SAS 9.0 (SAS, 2002). The two mating combinations were further compared using Wilcoxon's signed-rank test using SAS 9.0 (SAS, 2002).

\section{RESULTS}

The Kolmogorov-Smirnoff Test and Bartlett Tests revealed that the data were normally distributed with homogeneity of variance, which justified the usage of parametric oneway ANOVA.

\section{(i) The combination I- mate choice in unmated males}

The mating commenced within ten minutes in all the replicates. The multi-mated females accepted copulation readily with significantly less $(\mathrm{F}=8.47 ; \mathrm{P}=0.014)$ mating commencement time (3.3 \pm 0.6$)$ than unmated females $(5.5 \pm 0.7)$ (Table-1). The order of mate-choice (mate preference) in unmated males was Multi-mated > Twice mated > Single mated > Unmated females. Male ladybirds invested significantly more time 
$(\mathrm{F}=4.15 ; \mathrm{P}=0.045)$ in copula when mating occurred with multi-mated females $(22.0 \pm 3.0 \mathrm{~min})$ rather than with unmated females $(17.7 \pm 0.5 \mathrm{~min})$. The latent period and bouts in a copula increased as the mating status of females increased, i.e. lesser for unmated females $(4.0 \pm 0.0)(259.5 \pm 43.1)$ and greater for the multi-mated females (5.3 \pm 0.6$)(339 \pm 16.7)$. The fecundity was also significantly greater $(\mathrm{F}=13.68 ; \mathrm{P}=0.004)$ in the multi-mated females $(232.3 \pm 12.3$ eggs $)$ in comparison to unmated females (178.5 \pm 0.7 eggs). However, the percent egg viability did not differ significantly ( $\mathrm{F}=$ $0.70 ; \mathrm{P}=0.584)$ laid by all the females (unmated $(173 \pm 0.0)$, singly mated (195 \pm 4.2$)$, twice mated $(208 \pm 12.1)$, and multi-mated (227.7 \pm 9.3$)$ were equally viable.

Table 1: Mating and post-mating response when unmated males copulated with females of varying mating status

\begin{tabular}{|l|c|c|c|c|c|c|}
\hline $\begin{array}{l}\text { Female } \\
\text { mating status }\end{array}$ & $\begin{array}{c}\text { Mating } \\
\text { duration }\end{array}$ & $\begin{array}{c}\text { Time of mating } \\
\text { commencement } \\
(\mathbf{m i n})\end{array}$ & $\begin{array}{c}\text { Latent } \\
\text { period } \\
(\mathbf{s e c})\end{array}$ & $\begin{array}{c}\text { Bouts in } \\
\text { copula }\end{array}$ & $\begin{array}{c}\text { Fecundity } \\
\text { (in eggs) }\end{array}$ & $\begin{array}{c}\text { \% Egg } \\
\text { viability }\end{array}$ \\
\hline Unmated & $17.7 \pm 0.5^{\mathrm{b}}$ & $5.5 \pm 0.7^{\mathrm{a}}$ & $4.0 \pm 0.0^{\mathrm{b}}$ & $259.5 \pm 43.1^{\mathrm{b}}$ & $178.5 \pm 0.7^{\mathrm{c}}$ & $96.92 \pm 0.38^{\mathrm{a}}$ \\
\hline Single mated & $18.9 \pm 0.6^{\mathrm{ab}}$ & $5.0 \pm 0.0^{\mathrm{a}}$ & $5.0 \pm 1.4^{\mathrm{a}}$ & $294 \pm 25.5^{\mathrm{ab}}$ & $201.5 \pm 2.1^{\mathrm{bc}}$ & $96.76 \pm 1.08^{\mathrm{a}}$ \\
\hline Twice mated & $19.3 \pm 0.3^{\mathrm{ab}}$ & $3.7 \pm 0.6^{\mathrm{b}}$ & $4.7 \pm 1.5^{\mathrm{ab}}$ & $280 \pm 43.3^{\mathrm{ab}}$ & $213.0 \pm 10.6^{\mathrm{ab}}$ & $97.63 \pm 1.24^{\mathrm{a}}$ \\
\hline Multi-mated & $22.0 \pm 3.0^{\mathrm{a}}$ & $3.3 \pm 0.6^{\mathrm{b}}$ & $5.3 \pm 0.6^{\mathrm{a}}$ & $339 \pm 16.7^{\mathrm{a}}$ & $232.3 \pm 12.3^{\mathrm{a}}$ & $98.03 \pm 1.19^{\mathrm{a}}$ \\
\hline F-value & $\mathrm{F}=4.15 ;$ & $\mathrm{F}=8.47 ;$ & $\mathrm{F}=0.62 ;$ & $\mathrm{F}=2.63 ;$ & $\mathrm{F}=13.68 ;$ & $\mathrm{F}=0.70 ;$ \\
& $\mathrm{P}=0.045$ & $\mathrm{P}=0.014$ & $\mathrm{P}=0.628$ & $\mathrm{P}=0.144$ & $\mathrm{P}=0.004$ & $\mathrm{P}=0.584$ \\
\hline
\end{tabular}

Data are Mean \pm S.D.; Tukey's Range $=4.90$; d. f. $=3,9$

Different letters in the column denote that the data within the distribution is statistically significant.

\section{(ii) The combination II- mate choice in unmated females}

The presence of other males in proximity exerts a mating competition on males, hence the mating commenced within a minute in all the replicates. Adult multi-mated male copulated for a significantly $(\mathrm{F}=14.23 ; \mathrm{P}=0.004$; Table-2) longer duration $(28.1 \pm 0.1$ min) with virgin female (Figure-1). However, unmated males (19.11) copulated for a shorter duration. The order of male preference was; twice mated $>$ multi-mated $>$ single mated $>$ unmated males. The latent period decreased when mating occurred with multimated males (3.7 \pm 1.5$)$. However, bouts of copula increased significantly $(\mathrm{F}=11.54 ; \mathrm{P}=$ $0.007)$ as the mating status of males increased and were noted to be highest when mating occurred with multi-mated males $(366.7 \pm 11.4)$. The fecundity and egg viability in unmated females were not likely to be variable when they mated with males of different mating statuses. 


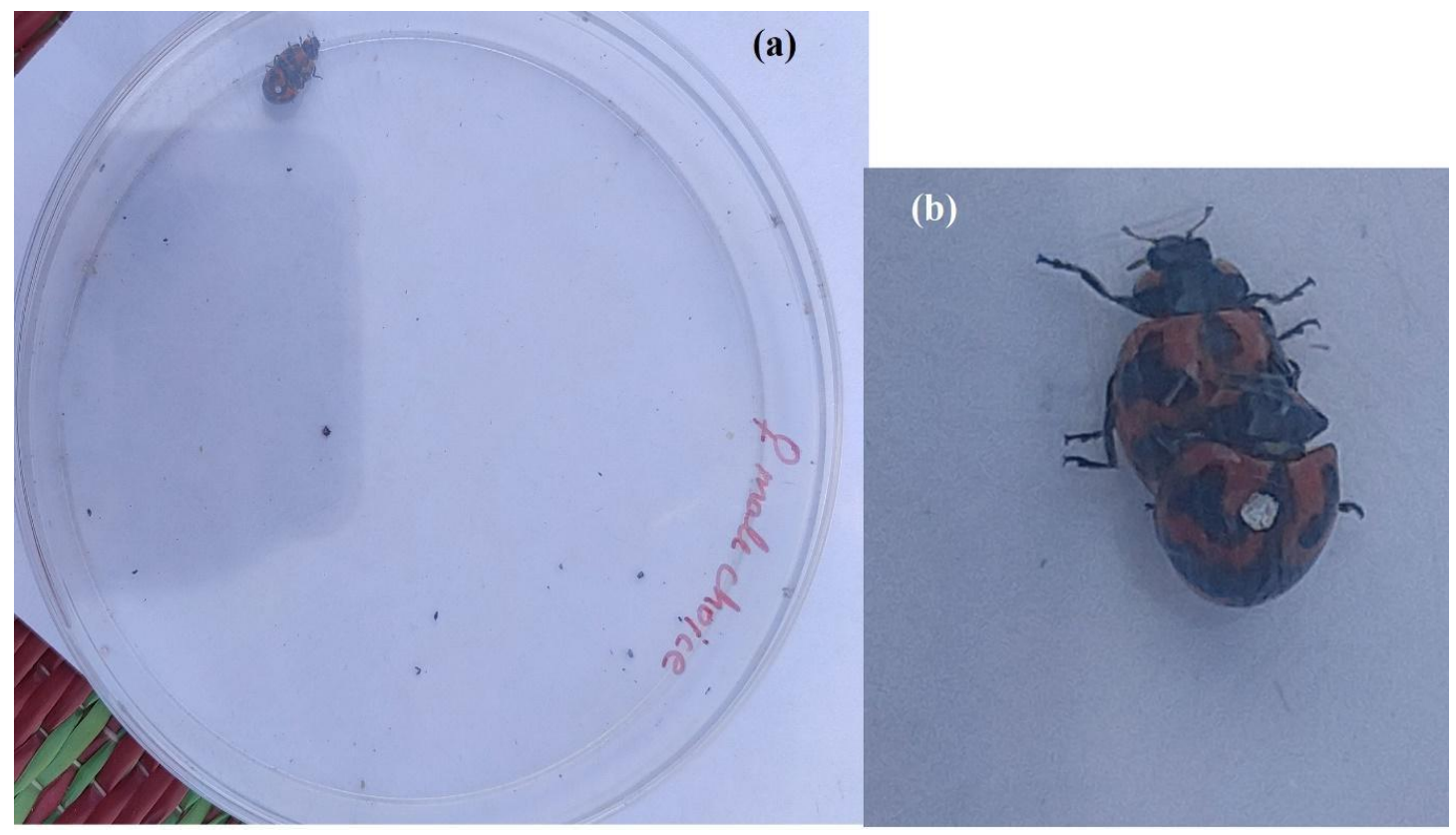

Figure 1: (a-b) Mating behaviour of $C$. transversalis when adult male of varying sexual status mated with virgin female.

Wilcoxon's signed-rank test further testified the significant difference the two mating combinations ( $\mathrm{i}$ and ii). The mating duration $(\mathrm{Z}=-2.988 ; \mathrm{P}=0.0014$; d.f. $=1)$, time of mating commencement $(\mathrm{Z}=4.059 ; \mathrm{P}=0.0001$; d.f. $=1)$, bouts in copula $(\mathrm{Z}=-1.778 ; \mathrm{P}$ $=0.037$; d.f. $=1)$, fecundity $(\mathrm{Z}=3.781 ; \mathrm{P}=0.0001$; d.f. $=1)$ and percent egg viability $(\mathrm{Z}=3.783 ; \mathrm{P}=0.0001$; d.f. $=1)$ in the two mating combinations ( $\mathrm{i}$ and ii) were significantly different. The latent period $(\mathrm{Z}=0.43$; $\mathrm{P}=0.333$; d.f. $=1)$, however, was not found to be statistically significant.

Table 2: Mating and post-mating response when unmated females copulated with males of varying mating status.

\begin{tabular}{|l|c|c|c|c|c|c|}
\hline $\begin{array}{l}\text { Male mating } \\
\text { status }\end{array}$ & $\begin{array}{c}\text { Mating } \\
\text { duration }\end{array}$ & $\begin{array}{c}\text { Time of mating } \\
\text { commencement } \\
(\text { min) }\end{array}$ & $\begin{array}{c}\text { Latent } \\
\text { period } \\
(\mathbf{s e c})\end{array}$ & $\begin{array}{c}\text { Bouts in } \\
\text { copula }\end{array}$ & $\begin{array}{c}\text { Fecundity } \\
\text { (in eggs) }\end{array}$ & $\begin{array}{c}\text { Egg } \\
\text { viability } \\
(\%)\end{array}$ \\
\hline Unmated & $19.11 \pm 0.0^{\mathrm{c}}$ & $1.0 \pm 0.0^{\mathrm{a}}$ & $4.0 \pm 0.00^{\mathrm{bc}}$ & $234.0 \pm 0.00^{\mathrm{c}}$ & $160.0 \pm 0.00^{\mathrm{a}}$ & $98.13 \pm 0.00^{\mathrm{a}}$ \\
\hline Single mated & $21.54 \pm 0.0^{\mathrm{bc}}$ & $1.0 \pm 0.0^{\mathrm{a}}$ & $6.0 \pm 0.00^{\mathrm{ab}}$ & $302.0 \pm 0.00^{\mathrm{bc}}$ & $162.0 \pm 0.00^{\mathrm{a}}$ & $98.15 \pm 0.00^{\mathrm{a}}$ \\
\hline Twice mated & $24.74 \pm 1.62^{\mathrm{b}}$ & $1.0 \pm 0.0^{\mathrm{a}}$ & $4.8 \pm 1.3^{\mathrm{b}}$ & $329.0 \pm 23.3^{\mathrm{b}}$ & $160.2 \pm 6.14^{\mathrm{a}}$ & $97.40 \pm 1.26^{\mathrm{a}}$ \\
\hline Multi-mated & $28.08 \pm 0.05^{\mathrm{a}}$ & $1.0 \pm 0.0^{\mathrm{a}}$ & $3.7 \pm 1.5^{\mathrm{c}}$ & $366.7 \pm 11.4^{\mathrm{a}}$ & $157.0 \pm 3.46^{\mathrm{a}}$ & $98.09 \pm 1.112^{\mathrm{a}}$ \\
\hline F-value & $\mathrm{F}=14.23 ;$ & - & $\mathrm{F}=0.88 ;$ & $\mathrm{F}=11.54 ;$ & $\mathrm{F}=0.32 ;$ & $\mathrm{F}=0.30 ;$ \\
& $\mathrm{P}=0.004$ & & $\mathrm{P}=0.503$ & $\mathrm{P}=0.007$ & $\mathrm{P}=0.814$ & $\mathrm{P}=0.823$ \\
\hline
\end{tabular}

Data are Mean \pm S.D.; Tukey's Range $=4.90$; d. f. $=3,9$

Different letters in the column denote that the data within the distribution is statistically significant. 


\section{DISCUSSION}

This study provides a clear understanding of the effect of olfactory stimuli as conspecific adults of different mating statuses on the reproductive parameters in the ladybird beetle, $C$. transversalis, and agrees with the previous study done by Singh et al. (2021). When the mate choice was provided to both unmated males and females, mating commenced rapidly for all the mating replicates. In unmated males, a fondness of mating choice was observed towards the previously mated females. However, adult males first tried to approach virgin females due to their ability to discriminate between females mating status that leads to increased male fitness, (Thomas, 2011) though females escaped from the male approach. Consequently, the male approached mated females, who were more receptive to copulate. Mated females copulated with unmated males to obtain larger ejaculate that replenishes the number of sperm as a direct benefit (Gershman, 2010). The mating commenced within a minute when males of different mating statuses were present in close vicinity and provided as mate choice for unmated females. Here, the presence of different males in proximity exerts a competition between males to copulate faster with females to hold a paternity share (Arnqvist \& Nilsson, 2000; Chaudhary et al., 2017).

The mating was noted for a longer duration when unmated males mated with multimated females (Pervez et al., 2021). However, females can escape from the male approach. Here, when the mating with previously mated males reduced sperm transfer and seminal fluid (Michaud et al., 2013) females copulate more and for a longer duration with unmated males because the large ejaculate with more seminal fluid replenishes the sperm content and stimulates fecundity and egg fertility that leads for better offspring quality in females (Pervez \& Maurice, 2011; Mirhosseini et al., 2014). The mating duration was also higher when unmated females were mated with multimated males. This is because mated males (both twice and multi-mated) under competition with conspecific males tried to mate more vigorously with unmated females for enhancing their paternity share (Dubey et al., 2018), and to avoid sperm competition by the unmated nature of females (Legrand, et al., 2019). The present study supports the view of Seeley \& Dukas (2011) in fruitfly that males gain from forcible mating with unmated and immature females. However, it does not allow mate - 
choosing in females, whom they wanted to mate, in the presence of conspecific males of different mating statuses.

Obata (1987) discovered the bouts (body shaking) as the indicator of sperm transfer. In the present study, bouts were noted to be higher, when unmated males copulated with multi-mated females. This is probably due to higher offspring production percentage by the last mated male (Chaudhry et al., 2016). Whereas higher bouts noted between unmated females and multi-mated males are probably to achieve more paternity by males, when there is no previous sperm competition or due to the presence of conspecific male pheromones.

The post-mating response, fecundity provides a clear understanding regarding reproductive success. Here unmated females were less fecund when they mated with males of different mating statuses. However, multi-mated females when mated with unmated males had higher fecundity with high egg viability. This suggested that the promiscuity in both sexes, in the case of ladybirds with multiple mating, leads to maximizing their reproductive success (Omkar \& Pervez, 2005; Singh et. al., 2020). This higher rate of egg production indicates the stimulation of ovariole development by the ejaculate.

\section{CONCLUSION}

We conclude that mate-choice in predaceous ladybirds may be largely affected by the mating status of conspecific mates. Mating commenced earlier in presence of different males in the arena than females. Unmated males courted firstly with virgin females by their discrimination ability. However, fondness in mated choice occurs towards multimated females. Mating may last for a longer duration when virgins mate with their multi-mated partners. Multi-mated females were more fecund than those mated once. Hence, the current information can be used for the quantitative mass-rearing of $C$. transversalis for the biocontrol of aphids and thereby enhancing crop productivity, sustainable development, and eco-protection.

We also conclude that this study under laboratory conditions provides less freedom to the ladybird beetles to choose their desired mates and completely depends upon experimenter criteria of mate choice. However, we predict that the field conditions may 
provide more opportunities for the beetles to choose better and desirable mates or whether to copulate or not. As the male and females can assess their mates' mating status, they can choose suitable mates for enhancing their reproductive success. In terms of females, under field/wild conditions, they can escape from the unwanted males (multi-mated) who have lower ejaculate and less sperm content compared to that of unmated males. However, males can have more opportunities to increase their paternity by mating with fewer resisting females.

\section{CONFLICTS OF INTEREST}

Authors have no conflicts of interests.

\section{ACKNOWLEDGEMENT}

Authors thank Dr. Meena Yadav, Department of Zoology, Maitreyi College, University of Delhi, Delhi for encouragements, and Science and Engineering Research Board, Department of Science and Technology, Govt. of India, New Delhi for financial assistance (EMR/2016/006296).

\section{REFERENCES}

Arnqvist, G., \& Nilsson, T. (2000). The evolution of polyandry: multiple mating and female fitness in insects. Animal Behaviour, 60(2), 145-164. DOI:10.1006/anbe. 2000.1446

Brown, A. E., Riddick, E. W., Aldrich, J. R., \& Holmes, W. E. (2006). Identification of $(-)-\beta$-caryophyllene as a gender-specific terpene produced by the multicolored Asian lady beetle. Journal of Chemical Ecology, 32(11), 2489-2499. https://doi.org/10.1007/s10886-006-9158-0

Cagliarini, A., \& Rush, A. (2011). Economic development and agriculture in India. RBA Bulletin, June, 15-22. https://econpapers.repec.org/scripts/redir.pf?u= https\%3A\%2F\%2Fwww.rba.gov.au\%2Fpublications\%2Fbulletin\%2F2011\%2Fju n\%2Fpdf\%2Fbu-0611-3.pdf;h=repec:rba:rbabul:jun2011-03

Chaudhary, D. D., Mishra, G., Omkar (2016). Last male wins the egg fertilization fight: A case study in ladybird, Menochilus sexmaculatus. Behavioural Processes, 131, 1-8. DOI:10.1016/j.beproc.2016.07.015

Chaudhary, D.D., Mishra, G. \& Omkar (2017) Strategic mate-guarding behaviour in ladybirds. Ethology, 123, 376-385. DOI:10.1111/eth.12606 
Dhawan, V. (2017). Water and agriculture in India. In Background paper for the South Asia expert panel during the Global Forum for Food and Agriculture, (Vol. 28).

Dubey, A., Singh, S., Omkar, \& Mishra, G. (2018). Paternity success in ladybirds: function of mating interval and order. Journal of Ethology, 36(2), 151-159. DOI:10.1007/s10164-018-0546-Z

Fox, C. W., Hickman, D. L., Raleigh, E. L., \& Mousseau, T. A. (1995). Paternal investment in a seed beetle (Coleoptera: Bruchidae): influence of male size, age, and mating history. Annals of the Entomological Society of America, 88(1), 100103. DOI:10.1093/aesa/88.1.100

Gershman, S. N. (2010). Large numbers of matings give female field crickets a direct benefit but not a genetic benefit. Journal of insect behavior, 23(1), 59-68. DOI:10.1007/s10905-009-9195-y

Gray, M. E., Ratcliffe, S. T., \& Rice, M. E. (2009). The IPM paradigm: concepts, strategies and tactics. Integrated Pest Management: Concepts, Tactics, Strategies \& Case Studies,.1-11. DOI:10.1017/CBO9780511626463.002

Guerrieri, E., \& Digilio, M. C. (2008). Aphid-plant interactions: a review. Journal of Plant Interactions, 3(4), 223-232. DOI:10.1080/17429140802567173

Hurst, G.D.D., Sharpe, R.G., Broomfield, A.H., Walker, L.E., Majerus, T.M.O., Zakharov, I.A. \& Majerus, M.E.N. (1995). Sexually transmitted disease in a promiscuous insect, Adalia bipunctata. Ecological Entomology, 20: 230-236. DOI:10.1111/j.1365-2311.1995.tb00452.x

Johansson, B. G., \& Jones, T. M. (2007). The role of chemical communication in mate choice. Biological Reviews, 82(2), 265-289. DOI:10.1111/j.1469-185X.2007.00009.x

Koli, P., \& Bhardwaj, N. R. (2018). Status and use of pesticides in forage crops in India. Journal of pesticide Science, 43(4), 225-232. DOI:10.1584/jpestics.D18004

Kumar, S., Sharma, A. K., Rawat, S. S., Jain, D. K., \& Ghosh, S. (2013). Use of pesticides in agriculture and livestock animals and its impact on environment of India. Asian Journal of Environmental Science, 8(1), 51-57.

Legrand, P., Vanderplanck, M., Lorge, S., Maesen, P., Lognay, G., Vilcinskas, A., ... \& Verheggen, F. J. (2019). Cuticular hydrocarbon composition does not allow Harmonia axyridis males to identify the mating status of sexual partners. Entomologia Generalis, 38(3), 211-224. DOI:10.1127/entomologia/2019/0552

Loxdale, H. D., Edwards, O., Tagu, D., \& Vorburger, C. (2017). Population genetic issues: new insights using conventional molecular markers and genomics tools. Aphids as crop pests, (Ed. 2), 50-80. DOI: 10.1079/9781780647098.0050

Michaud, J. P., Bista, M., Mishra, G., \& Singh, O. (2013). Sexual activity diminishes male virility in two Coccinella species: consequences for female fertility and 
progeny development. Bulletin of entomological research, 103(5), 570-577. DOI:10.1017/S0007485313000199

Mirhosseini, M. A., Michaud, J. P., Jalali, M. A., \& Ziaaddini, M. (2014). Paternal effects correlate with female reproductive stimulation in the polyandrous ladybird Cheilomenes sexmaculata. Bulletin of Entomological Research, 104(4), 480-485. DOI:10.1017/S0007485314000194

Navodita, M., Pervez, A., Kumar, A., \& Ramteke, P. W. (2011). Duration of development and survival of larvae of Coccinella transversalis fed on essential and alternative foods. European Journal of Environmental Sciences, 1(1). DOI:10.14712/23361964.2015.61

Nayak, S., Sahoo, A., Kolanthasamy, E., \& Rao, K. (2020). Role of pesticide application in environmental degradation and its remediation strategies. Environmental Degradation: Causes and Remediation Strategies, 1, 36. DOI:10.26832/aesa-2020-edcrs-03

Obrycki, J. J., Harwood, J. D., Kring, T. J., \& O’Neil, R. J. (2009). Aphidophagy by Coccinellidae: application of biological control in agroecosystems. Biological control, 51(2), 244-254. DOI:10.1016/j.biocontrol.2009.05.009

Omkar \& Mishra, G. (2005). Mating in aphidophagous ladybirds: costs and benefits. Journal of Applied Entomology, 129(8), 432-436. DOI:10.1111/j.14390418.2005.00996.x

Omkar \& Sahu, J. (2012). Costs and benefits of reproduction in predaceous ladybird: Effect of multiple matings on reproduction and offspring development. Journal of Asia-Pacific Entomology, 15(2), 219-224. DOI:10.1016/j.aspen.2011.12.002

Perry, J. C., \& Tse, C. T. (2013). Extreme costs of mating for male two-spot ladybird beetles. Plos One, 8(12), e81934. DOI:10.1371/journal.pone.0081934

Pervez, A. \& Omkar (2005). Functional responses of coccinellid predators: an illustration of a logistic approach. Journal of Insect Science, 5(1). DOI:10.1673/031.005.0501

Pervez, A., \& Maurice, N. (2011). Mate choice and polyandry benefit reproduction and progeny fitness in the ladybird Hippodamia variegata (Goeze). European Journal of Environmental Sciences, 1(1), 19-23. DOI:10.14712/23361964.2015.60

Pervez, A., Jahan, M. \& Monalisa (2021). Courtship behaviour and mating refusals in an aphidophagous ladybird, Coccinella transversalis. International Journal of Tropical Insect Science, 1-7. DOI:10.1007/s42690-021-00536-1

Pervez, A., Omkar, \& Harsur, M. M. (2020). Coccinellids on crops: Nature's gift for farmers. In Innovative Pest Management Approaches for the 21st Century (pp. 429-460). Springer, Singapore. DOI:10.1007/978-981-15-0794-6_21

Rebijith, K. B., Asokan, R., Hande, H. R., Joshi, S., Surveswaran, S., Ramamurthy, V. V., \& Krishna Kumar, N. K. (2017). Reconstructing the macroevolutionary 
patterns of aphids (Hemiptera: Aphididae) using nuclear and mitochondrial DNA sequences. Biological Journal of the Linnean Society, 121(4), 796-814. DOI:10.1093/biolinnean/blx020

Rondoni, G., Borges, I., Collatz, J., Conti, E., Costamagna, A. C., Dumont, F., ... \& Cock, M. J. (2021). Exotic ladybirds for biological control of herbivorous insects-a review. Entomologia Experimentalis et Applicata, 169(1), 6-27. DOI:10.1111/eea.12963

Roy, H., \& Wajnberg, E. (2008). From biological control to invasion: the ladybird Harmonia axyridis as a model species. BioControl, 53(1), 1-4. DOI:10.1007/978$1-4020-6939-0$

Seeley, C., \& Dukas, R. (2011). Teneral matings in fruit flies: male coercion and female response. Animal Behaviour, 81(3), 595-601. https://doi.org/10.1016/j.anbehav. 2010.12.003

Shahid, M., Siddiqui, A., Omkar, \& Mishra, G. (2016). Mating alters the rate of development of ovarioles in the ladybird, Propylea dissecta (Coleoptera: Coccinellidae). European Journal of Entomology, 113, 44. DOI:10.14411/eje. 2016.005

Shukla, A. \& Jadhav, D. S. (2014). Biology of Coccinella transversalis (Fabricius) on different aphid species. The Bioscan, 9(1), 17-22. DOI:10.5958/09748172.2015 .00039 .5

Singh, P., Mishra, G. \& Omkar (2020). Impact of female mating status and female familiarity with remating interval on the reproductive success of Propylea dissecta (Mulsant) (Coleoptera: Coccinellidae). Animal Biology, 70(3), 271-287. DOI:10.1163/15707563-bja10002

Singh, S., Mishra, G. \& Omkar (2021). Mating status of coexisting conspecific individuals modulate reproduction in a ladybird, Menochilus sexmaculatus. Animal Biology, 71(2), 197-214. DOI:10.1163/15707563-bja10015

Smith, J. M., \& Harper, D. (2003). Animal signals. Oxford University Press.

Thomas, M. L. (2011). Detection of female mating status using chemical signals and cues. Biological Reviews, 86(1), 1-13. DOI:10.1111/j.1469-185X.2010.00130.x

Thornhill, R., \& Alcock, J. (2013). The evolution of insect mating systems. Harvard University Press.

Uhía, E., \& Rivera, A. C. (2005). Male damselflies detect female mating status: importance for postcopulatory sexual selection. Animal Behaviour, 69(4), 797804. DOI:10.1016/j.anbehav.2004.08.005

Van Lenteren, J. C. (2012). The state of commercial augmentative biological control: plenty of natural enemies, but a frustrating lack of uptake. BioControl, 57(1), 120. DOI:10.1007/s10526-011-9395-1 
Verheggen, F., Cherif, A., \& Martin, C. (2020). The production of sex pheromone in lady beetles is conditioned by presence of aphids and not by mating status. Journal of Chemical Ecology, 46(7), 590-596. DOI:10.1007/s10886-020-01197-z

How to cite this article: Jahan, M., \& Pervez, A. (2021). Manipulating mate-choice for a quantitative augmentation of a biological control agent, Coccinella transversalis Fabricius. Vantage: Journal of Thematic Analysis, 2(2):

DOI: https://doi.org/10.52253/vjta.2021.v02i02.06

(C) The Author(s) 2021.

This work is licensed under a Creative Commons Attribution 4.0 International License which permits its use, distribution and reproduction in any medium, provided the original work is cited. 